\title{
The amortization of vibrations on machines - case study
}

\author{
Ahmet Latifi *, Arsim Abazi, Astrit Shartari \\ Mechanical and Computer Engineering Department, Public University of Mitrovica PIM 40000 Mitrovica, Republic of Kosova \\ *Corresponding author E-mail: ahmet.latifi@umib.net
}

\begin{abstract}
When determining the static rigidity of the machine, only loads of constant forces are taken into account. However, machine details are not loaded only with static forces but also with external and internal dynamic forces. Components of static forces affect the form errors, while dynamic instability, and as a result of dynamic forces have negative impact on: the severity of processed surface, the wear of the metal cutting tool, wear of the machine details and productivity.
\end{abstract}

Keywords: Vibration; Amortization; Isolation; Machine; Cutting Tool; Wear; Force.

\section{Introduction}

The vibration phenomenon on cutting tool machines, presents a significant problem, as the effect of vibration impact: the inaccuracy of the machine work, the early consumption of the cutting tool and eventually damage machine elements. The machine performance is accompanied by violent vibrations discussed by Thomson et.al [2] and Weaver et.al [3] for certain work modes appear some self-caused vibrations.

The system consists of (k), absorber (b) and mass (m) in which operates the external force $(\mathrm{F})$;

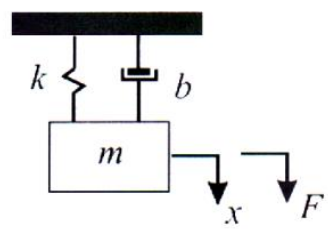

Fig. 1: The Operation of the External Force on the System.

Vibrating system model of the first order:

$m \ddot{x}+b \dot{x}+c x=F_{o} \sin \omega t$

Own source frequency:

$\omega_{n}=\frac{k}{m}$

Critical amortization (the border between periodic and Non-periodic system vibrations).

$b_{k}=2 m \omega_{n}$

The measure will move according to the law:

$x=x_{o} \sin (\omega t-\varphi)$ $\frac{\mathrm{x}}{\mathrm{x}_{\text {stat }}}=\frac{\frac{\mathrm{F}_{\mathrm{o}}}{\mathrm{k}}}{\sqrt{\left(1-\frac{\omega^{2}}{\omega_{\mathrm{n}}^{2}}\right)^{2}+\left(2 \frac{\mathrm{b}}{\mathrm{b}_{\mathrm{k}}} \cdot \frac{\omega}{\omega_{\mathrm{n}}}\right)^{2}}}$

The angle of the voting phase:

$\operatorname{tg} \varphi=\frac{2 \frac{b}{b_{k}} \cdot \frac{\omega}{w_{n}}}{1-\frac{\omega^{2}}{\omega_{n}^{2}}}$

$z=\frac{f}{f_{n}}$

Extinction coefficient:

$\mathrm{h}=\frac{\mathrm{n}}{\omega}$

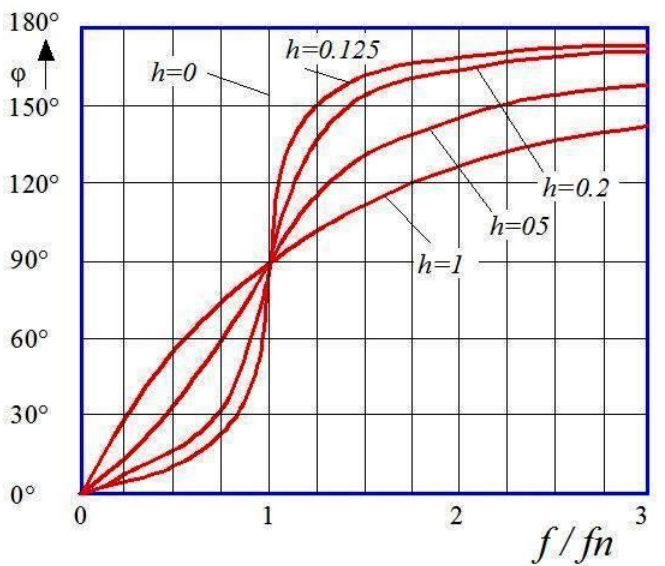

Fig. 2: The Angle Dependence of the Changing Phase $\Phi$ in Relation with Harassment Coefficient.

Reinforcing dynamic factor: 


\section{Isolation of vibrations - prevention of transmitting vibration in the surroundings}

The system on flexible manner is connected to the basement and the cutting dynamic force expressed from Tony et.al [4] how does operates on it as shown in the figure below.

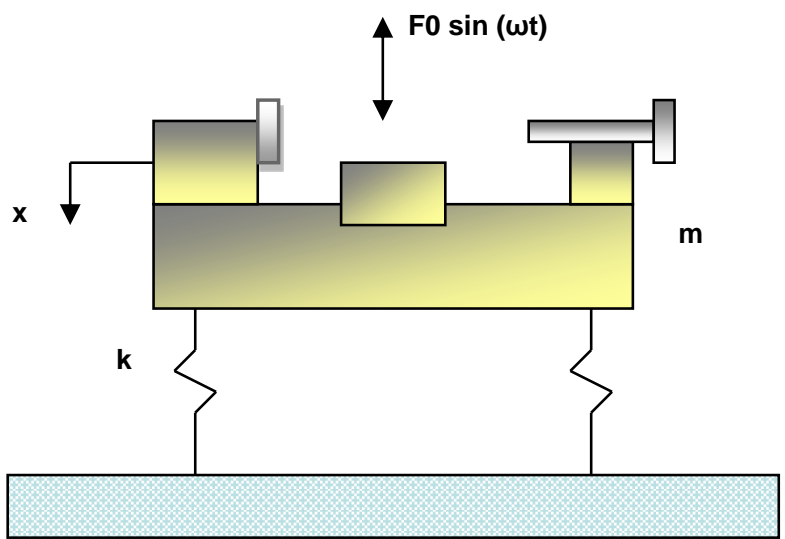

Fig. 3: Flexible Connection of the System with the Basement.

When the button rigidity $(\mathrm{K})$ is too great, the ownfrequency is too great as well, so we see the reinforcement dynamic force is one peace, which means that total value of the exciting force is transmitted to the basement. It is necessary that the supportive buttons get chosen on that way that the own frequency is much smaller than the exciting forces. If the own frequency of the system is as $1 / 5$ of the exciting force frequency then it gets:

$\frac{\text { TransferredForce }}{\text { ExcitingForce }}=\frac{1}{24}$ (thisiscalledthetransferingreport)

In some cases this ratio should be even smaller. The system on flexible-viscous manner is connected to the basement and the cutting dynamic force operates on it, Cheng [5].

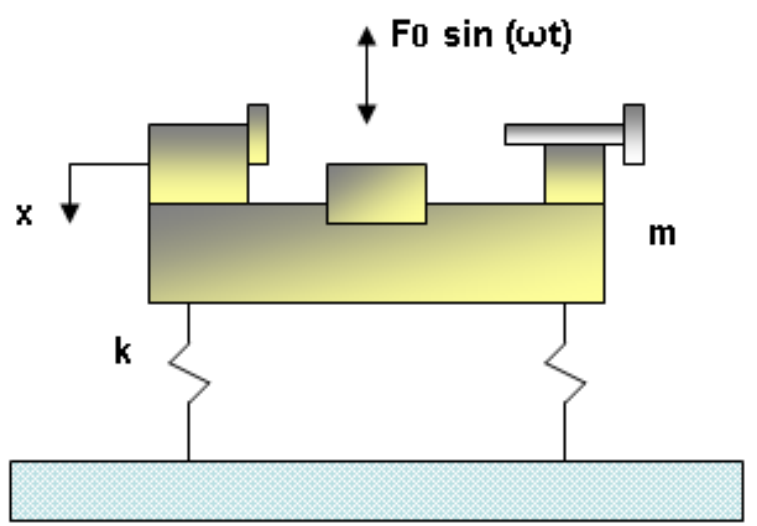

Fig. 4: Flexible-Viscous Connection System to the Basement.

Carried force:

$F_{O}=\frac{\sqrt{1+\left(\frac{b \omega}{k}\right)^{2}}}{\sqrt{\left(1-\frac{\omega^{2}}{\omega_{n}^{2}}\right)^{2}+\left(2 \frac{b \omega}{b_{k} \omega_{n}}\right)^{2}}}$

Exciting Force:

Carrying report $=\frac{\text { Carried force }}{\text { Exciting Force }}=\frac{\sqrt{1+\left(2 \frac{\mathrm{b} \omega}{\mathrm{b}_{\mathrm{k}} \omega_{\mathrm{n}}}\right)^{2}}}{\left(1-\frac{\omega^{2}}{\omega_{\mathrm{n}}^{2}}\right)^{2}+\left(2 \frac{\mathrm{b}}{\mathrm{b}_{\mathrm{k}}} \frac{\omega}{\omega_{\mathrm{n}}}\right)^{2}}$ $\omega>\omega_{\mathrm{n}} \sqrt{2}$

Whereas the amortization has advantages if:

$\omega<\omega_{\mathrm{n}} \sqrt{2}$

\subsection{Relative amortization system}

Putting the amortization passive elements on the structure of the cutting tool machine reduces the oscillations of all its constituents.

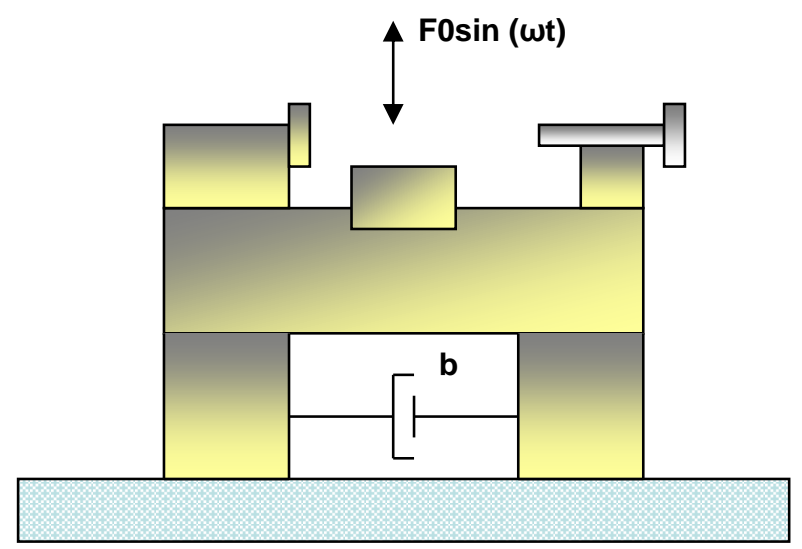

Fig. 5: Putting the Amortization Elements on the Carrying Structure.

In general, to reduce the transmission of vibrations through the structure of the machine tool it is necessary to use materials which have a high degree of self amortization. Good quality as conventional material for building the transmitting structures of the cutting tool machines has molding iron, and then the polymers gets cemented as a new material.

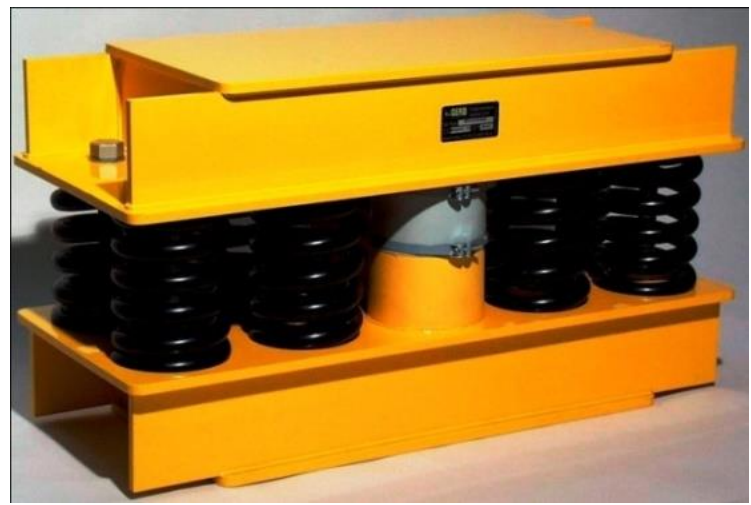

Fig. 6: Vibration Amortization of the Cutting Tool Machine.

\section{Laboratory measurements}

Measurements of vibrations on the main axis of turning machines V-Turn and Turnado 230 the results which are obtained by Abazi [1], during material processing steel $\mathrm{Ck} 35$, according to DIN's, with dimensions $\varnothing 55$ and $1=550$, by the processing selected mode on the shown table 1 , by the cutting tool with the following characteristics: $\alpha=45^{\circ}, \gamma=90^{\circ}, \beta=60^{\circ}, \mathrm{r}=1.2[\mathrm{~mm}]$. 
Table 1: Laboratory Measurements: Vibration Measurements on the Main Axis on the Turning Machines V-Turn and Turnado 230

\begin{tabular}{llll}
\hline \multirow{2}{*}{ No. } & $\begin{array}{l}\text { Processing Regime } \\
\mathrm{v}(\mathrm{m} / \mathrm{min})\end{array}$ & $\mathrm{f}(\mathrm{mm} / \mathrm{rev})$ & $\mathrm{t}(\mathrm{mm})$ \\
\hline 1 & 300 & 0.055 & 0.5 \\
2 & 700 & 0.055 & 0.5 \\
3 & 300 & 0.10 & 0.5 \\
4 & 700 & 0.10 & 0.5 \\
5 & 300 & 0.055 & 1.5 \\
6 & 700 & 0.055 & 1.5 \\
7 & 300 & 0.10 & 1.5 \\
8 & 700 & 0.10 & 1.5 \\
9 & 500 & 0.085 & 1.0 \\
10 & 500 & 0.085 & 1.0 \\
11 & 500 & 0.085 & 1.0 \\
12 & 500 & 0.085 & 1.0 \\
\hline
\end{tabular}

\begin{tabular}{lll}
\hline No & Torno V-Turn & Torno Turnado230 \\
\hline 1 & Vibrations f $[\mathrm{Hz}]$ & \\
2 & 0.02 & 0.02 \\
3 & 0.01 & 0.01 \\
4 & 0.02 & 0.02 \\
5 & 0.01 & 0.01 \\
6 & 0.02 & 0.02 \\
7 & 0.02 & 0.02 \\
8 & 0.01 & 0.01 \\
9 & 0.02 & 0.02 \\
10 & 0.01 & 0.01 \\
11 & 0.01 & 0.01 \\
12 & 0.01 & 0.01 \\
& 0.01 & 0.01 \\
\hline
\end{tabular}

\subsection{Machines classification based on the vibration in- tensity}

According to the provisions arising from international standards and technological energetic machines are divided into several groups, and as a criterion of intensity of vibration was taken vibrations speed $\mathrm{v}(\mathrm{m} / \mathrm{s})$. Talking about the harmonic vibrations, the vibration amplitude serves as the defining mass of allowed vibrations. Based on the vibration intensity, machines are classified into the following groups [1]:

Group K (small machines)- here are included specific details of the machines and mechanisms, which are rigid - related on working condition, such as for example electro motors with power up to $15 \mathrm{kw}$.

Group M (average machines) - here are included machines without any specific plinth such as for example electro motors with power of $15-75 \mathrm{kw}$.

Group G (large machines) - large machines and motors located on rigid and heavy plinths, such as for example turbo groups.

Group D - Machines and generators are located on plinths, with high adaptive balancing measures.

Group S - Machines and generators are located on plinths with low adaptive balancing measures (Flexible plinths), such as centrifuges, vibrating sieves and machines for investigation of dynamic materials etc.
Table 2: Shows the Vibration Intensity for Machine Groups Depending on Vibration Effective Speed $v_{e f}$ and Equivalent $\boldsymbol{v}_{\text {eq. }}$.

\begin{tabular}{llllll}
$\begin{array}{l}\mathrm{V}_{\text {ef }} \\
(\mathrm{mm} / \mathrm{s})\end{array}$ & $\begin{array}{l}\mathrm{V}_{\text {eq }} \\
(\mathrm{mm} / \mathrm{s})\end{array}$ & $\begin{array}{l}\text { Group } \\
\mathrm{K}\end{array}$ & $\begin{array}{l}\text { Group } \\
\mathrm{M}\end{array}$ & $\begin{array}{l}\text { Group } \\
\mathrm{G}\end{array}$ & $\begin{array}{l}\text { Group } \\
\mathrm{D}\end{array}$ \\
\hline 0.28 & 0.4 & $\mathrm{~A}$ & $\mathrm{~A}$ & $\mathrm{~A}$ & $\mathrm{~A}$ \\
0.45 & 0.63 & & & & \\
0.71 & 1 & & & & \\
1.12 & 1.6 & $\mathrm{~B}$ & & & \\
1.8 & 2.5 & & $\mathrm{~B}$ & & \\
2.8 & 4 & $\mathrm{C}$ & & $\mathrm{B}$ & \\
4.5 & 6.5 & $\mathrm{C}$ & $\mathrm{C}$ & $\mathrm{B}$ \\
7.1 & 10 & & & $\mathrm{C}$ & \\
11.2 & 16 & & & & $\mathrm{C}$ \\
18 & 25 & $\mathrm{D}$ & & & \\
28 & 40 & & $\mathrm{D}$ & $\mathrm{D}$ & $\mathrm{D}$ \\
45 & 63 & & & & \\
\hline
\end{tabular}

A-Very good or good; B-useful; C-still permitted but improvement is required; D- impermissible

\section{Conclusion}

Identification of the machine dynamic work during the designing phase is done in order to ensure the necessary dynamic stability of the machine, while in the exploitation phase in order to determine the dynamic stability area of the cutting regime. The appearance of the dynamic forces is natural and can be deployed as follows:

a) External incentive

1) The generated forces outside the machine effects from the lumbar while transferring to the machine through the machine base.

2) Forces generated in the machine

3) Due to non-rotational equilibrium details, periodic movements of the details, uneven work, errors during operation of the transmission system.

4) Due to intermittent cutting (processing by milling, details turning with axial channels).

b) Own incentive (Own incentive vibrations) appear during the cutting process, as result of joining of the machine elastic system during the cutting process.

\section{References}

[1] Msc. Arsim Abazi "The impact of vibrations on the severity of the work surface during the turning process" Master Work-Mitrovica 2015.

[2] Thomson, W. and Dahleh, M., 1998, Theory of Vibration with Application, 5th Ed., Prentice Hall, Upper Saddle River, NJ.

[3] Weaver, Jr., W., Timoshenko, S., and Young, D., 1990, Vibration Problems in Engineering, 5th Ed., John Wiley and Sons, New York, NY.

[4] Tony L.Schmitz, K. Scot Smith-“Machining Dynamics” NY 2009. https://doi.org/10.1007/978-0-387-09645-2.

[5] PhD, Kai Cheng-"Machining Dynamics Fundamentals, Applications and Practices" London 2009. 